\title{
A regenerated fiber from rennet-treated casein micelles
}

\author{
Sebastian Thill ${ }^{1}$ - Thomas Schmidt ${ }^{2} \cdot$ Dominik Wöll $^{2} \cdot$ Ronald Gebhardt ${ }^{1}$ \\ Received: 14 August 2020 / Accepted: 16 December 2020 / Published online: 6 January 2021 \\ (C) The Author(s) 2021
}

\begin{abstract}
Casein as the major protein of milk is a promising protein source for biopolymer fibers. Current casein-based fibers are fabricated by dissolving caseins in alkaline media and wet spinning in a coagulation bath containing harsh chemicals. In milk, casein is present in so-called casein micelles (CMs). Based on the rennet-induced aggregation, we developed a process that can be applied for the spinning of micellar casein fibers in a sustainable way without the use of harsh chemicals. Fabricated fibers show a surface with a characteristic microstructure, which can also be detected embedded in a network structure inside the fiber. The fibers are stable under acidic and neutral conditions and decompose in alkaline media down to aggregates with sizes comparable to the characteristic microstructure. The so far reached tensile properties of the micellar fiber are between low and mid double-digit percentage range compared to casein azlons.
\end{abstract}

Keywords Aggregation · Protein fiber · Casein micelles · Rennet enzyme

\section{Introduction}

Since the early twentieth century, a lot of different approaches have been followed to produce fibers from regenerated proteins such as silk fibroin, collagen, gelatin, or milk protein. These fibers, known as "azlons," were developed to compete with other natural protein fibers such as wool or silk in order to improve material properties, provide new functionalities, or reduce the ecological production footprint. According to Brooks [1], three different generations of regenerated protein fibers can be identified, each developed in response to contemporaneous economic and social factors. They are produced by dissolving the proteins in alkaline media and forcing the solutions through a spinneret into an acidic coagulation bath followed by an additional crosslinking step [2-4]. Commonly crosslinking is performed with formaldehyde. Recently, other more biocompatible crosslinking agents such as citric acid or enzymatic treatment are used for post-treatment. $[5,6]$ In the bioinspired spinning process, regenerated silk fibers are

Ronald Gebhardt

ronald.gebhardt@avt.rwth-aachen.de

1 Chair of Soft Matter Process Engineering (AVT.SMP), RWTH Aachen University, Aachen, Germany

2 Institute of Physical Chemistry (IPC), RWTH Aachen University, Aachen, Germany formed from a silk protein solution, which is aligned along the spinning jet axis by elongation forces [7]. In the natural spinning process, silk proteins form micelle-like configurations with anisotropic liquid crystalline properties which, after shear stress and dehydration, become fibers when pulled out $[7,8]$.

Casein, the main protein in milk ( $80 \%)$, can be described as a group of natively unfolded or intrinsically disordered molecules [9]. Until now, casein could only be used in combination with other additives for the production of regenerated protein fibers. In milk, the caseins form the so-called casein micelles (CMs) due to their poor solubility properties. CMs are roughly spherical, colloidal structures with diameters ranging from 50 to $600 \mathrm{~nm}$ [10]. Their broad size distribution can be described by a log-normal distribution [11]. CMs are complex association colloids composed of four natively unfolded phosphoproteins $\alpha_{\mathrm{S}^{-}}, \alpha_{\mathrm{S}^{-}}, \beta-$, and $\mathrm{K}$-casein and colloidal calcium phosphate. $[10,12,13]$ Their primary structure shows distinct hydrophilic and hydrophobic regions, which led to their consideration as diblock copolymers within the dual binding model of hydrophilic and hydrophobic interactions [14, 15]. According to the model, the hydrophobic regions of the caseins associate with each other, while phosphoserine-rich spots in the hydrophilic blocks associated with colloidal calcium phosphate particles distributed in the micelle. A comprehensive experimental proof of the dual-binding hypothesis was provided by in-situ light scattering studies under high 
hydrostatic pressure [16]. The contribution of hydrophobic interactions to overall stability was singled out from the electrostatic interactions by temperature-dependent measurements, which were sensitive to variations in $\mathrm{pH}$ and calcium concentration. On the outside of the CM, $\mathrm{K}$-casein builds up a so-called "hairy" layer with a thickness of about 5-10 nm. The hydrophilic C-terminal part (casein macropeptide, CMP) expands into the surrounding solution, while the hydrophobic Nterminal part of the molecule is anchored in the micelle. The K-casein surface layer thus formed stabilizes the CM sterically and prevents unlimited growth by shielding further hydrophobic contacts $[11,12]$. After enzymatic cutting of the $\mathrm{K}$-casein brush, CMs can be converted into so-called para-casein micelles (para-CM), which agglomerate at ambient temperature and form a gel. During this process, chymosin, the main enzyme of the rennet extract from the calf's stomach, specifically cleaves K-casein at the $\mathrm{Phe}_{105}-\mathrm{Met}_{106}$ bond [17]. The hydrophilic C-terminal part of the $\mathrm{K}$-casein is released into the serum while the $\mathrm{N}$-terminal part remains attached to the micelle. If the process is carried out at temperatures above $18{ }^{\circ} \mathrm{C}$, after hydrolysis of about $80 \%$ of the $\mathrm{K}$-casein, the micelles lose their colloidal stability and begin to aggregate [11]. The subsequent sol-gel transition takes place via the formation of large primary clusters, which then combine in a second step to form a space-filling cluster gel $[17,18]$. The aggregation strongly depends on environmental conditions such as temperature, $\mathrm{pH}$, and $\mathrm{Ca}^{2+}$ concentration [19]. The forces stabilizing the aggregates are not yet fully known but hydrophobic interactions are probably major contributors, because coagulation hardly takes place at low temperatures $[20,21]$. However, when the enzymatic cleavage is carried out in the cold, the para-CMs keep their colloidal stability, so that they can be used specifically for controlled structure formation [22] and for studying the rennet-induced coagulation process [23].

So far, only non-micellar sodium or calcium caseinate has been used as raw material to produce regenerated casein fibers. Sudha et al. used casein/soy blends to fabricate fibers of 100-250 $\mu \mathrm{m}$ diameter in a wet-spinning process [24]. SEM images showed that pure casein fibers had a very smooth surface, while hybrid fibers showed increasing surface roughness with increasing soy content. Yang and Reddy employed a wet-spinning process using sodium sulfate and acetic acid as coagulation agents [6]. Subsequent crosslinking of the fibers with citric acid and sodium hypophosphite followed by a thermal treatment led to the enhanced mechanical stability of the fibers. Tomasula et al. used casein/pullulan blends to produce sub-micrometersized fibers in an electrospinning process [25].

Here we show a simple process how fibers can be produced from rennet-treated casein micelles in a wet-spinning process without further additives. We report on typical microstructural features inside and on the surface of the fiber as well as on its solubility behavior and mechanical properties.

\section{Material and methods}

\section{Sample preparation}

We obtained fresh whole milk from a local dairy farm (Soerser Milchkännchen) and skimmed it by centrifugation. After skimming, the CMs were isolated by ultracentrifugation at ambient temperature in an Optima XPN-80 (Beckman Coulter) ultracentrifuge at $70000 \mathrm{xRCF}$ for $60 \mathrm{~min}$. The casein pellet obtained was resuspended with stirring at $37^{\circ} \mathrm{C}$ for $2 \mathrm{~h}$ in simulated milk ultrafiltrate (SMUF) [26]. To prevent microbial growth, sodium azide was added in an amount of $0.05 \%(\mathrm{w} / \mathrm{w})$. However, this had no further influence on the subsequent structure formation processes as further experiments have shown. The $\mathrm{CM}$ concentration was measured gravimetrically by film drying and adjusted to $5 \%(\mathrm{w} / \mathrm{w})$ by dilution with SMUF. To produce non-aggregated para-CMs, the $\mathrm{CM}$ solution was incubated with $50 \mathrm{IMCU} \mathrm{L}^{-1}$ rennet enzyme (CHY-MAX-M, Chr. Hansen A/S) at $5{ }^{\circ} \mathrm{C}$ for $24 \mathrm{~h}$. Fiber fabrication is described under results and discussion.

\section{Fluorescence microscopy}

For labeling, $15 \mathrm{~mL}$ of a $5 \%(\mathrm{w} / \mathrm{w}) \mathrm{CM}$ solution was incubated with $20 \mu \mathrm{L}$ of the fluorescence dye Atto 647 N-NHS (Atto-tec $\mathrm{GmbH} ; 3.95 \mathrm{mM}$ in DMSO, dried (Merck Chemicals GmbH)) under agitation at $5{ }^{\circ} \mathrm{C}$. The reactive Atto NHS-esters react with amine groups of the casein proteins and covalently label the CMs. Excessive dye was removed by a further ultracentrifugation step. The labeled CM solution was $100 \times$ diluted in unlabeled $\mathrm{CM}$ solution and subsequently incubated with $50 \mathrm{IMCU} \mathrm{L}^{-1}$ rennet enzyme at $5{ }^{\circ} \mathrm{C}$ for $24 \mathrm{~h}$. After fabrication, the fibers were stored in SMUF until the microscopic experiments were performed. The fibers were placed onto a glass coverslip with a thickness of $170 \mu \mathrm{m}$ (borosilicate glass, high precision, no. $1.5 \mathrm{H}$, Marienfeld) and fixed using a spacer (Grace Bio-Labs SecureSeal ${ }^{\mathrm{TM}}$ imaging spacer, diam. $\times$ thickness $9 \mathrm{~mm} \times 0.12 \mathrm{~mm}$, Sigma-Aldrich). Additionally, $10 \mu \mathrm{l}$ of SMUF was dropped onto the fiber to keep it wet. The coverslip was placed onto a $x y z$-piezo table (P-545.3R7, Physik Instrumente) to move the sample. A VisiScope Spinning-Disc-DC Confocal System (Visitron Systems $\mathrm{GmbH}$ ) consisting of an inverted microscope (Nikon Eclipse $\mathrm{T} i$-E) in combination with a $100 \times / 1.40$ oil immersion objective (HP Plan, Nikon) and a confocal spinning disc unit (CSU$\mathrm{X} 1 \mathrm{FW}$, Yokogawa) was employed to acquire the fluorescence microscopy images. For excitation, two $640 \mathrm{~nm}$ single-mode diode lasers (each $200 \mathrm{~mW}$, iBeam smart 640-S-HP, Toptica) were used. To separate the emission from the excitation light, a quad-line beamsplitter (Di01-T405/488/568/647, Semrock) was applied. The emission light was filtered by an additional bandpass filter (ET700/75, Chroma). The exposure time of the EMCCD camera (Andor iXON Ultra 888) was set to $20 \mathrm{~ms}$. 


\section{Electron microscopy}

Experiments were carried out using a TM3030 Plus tabletop microscope (Hitachi High-Tech Corporation). Prior to the measurements, the fibers were dried and fixed on the sample holder using conductive tape. The acceleration voltage was set to $15 \mathrm{kV}$ and SE (secondary electron) image mode was used.

\section{Swelling experiments}

Dried fibers were placed on a coverslip (borosilicate glass, High Precision, No. $1.5 \mathrm{H}$, Marienfeld) and $100 \mu \mathrm{L}$ of $1 \mathrm{M}$ sodium hydroxide (VWR chemicals) was added. Images were recorded on a Leica DMI LED microscope (Leica Microsystems) using a 2.3 MP CMOS camera (Basler AG).

\section{Stress-strain experiments}

Tensile tests of the fiber were conducted on an AGS-X Autograph (Shimadzu) equipped with a $5 \mathrm{~N}$ load cell. Dried fibers were prepared on a frame which was clamped into the rubber jaws. The active tested fiber length was $10 \mathrm{~mm}$. During the test, an initial force of $0.02 \mathrm{~N}$ was applied followed by a constant deformation at $50 \mu \mathrm{m} \mathrm{s}^{-1}$. The sampling rate was set to $100 \mathrm{~Hz}$. The measurements were performed at $21{ }^{\circ} \mathrm{C}$ and relative humidity of $30 \%$.

\section{Results and discussion}

Figure 1 shows the prototype setup for fiber production. The para-CM solution, prepared by cold-renneting, is spun through a cannula into a $100 \mathrm{mM}$ calcium chloride coagulation bath at a temperature of $55^{\circ} \mathrm{C}$ (Fig. 1a). After a holding time of $10 \mathrm{~min}$, the fiber is drawn out of the coagulation bath and then dried in the air (Fig. 1b). These conditions were found to be most suitable for the fiber fabrication, as the fibers were not stable when extruded in a coagulation bath at ambient temperature or a calcium-free coagulation bath.

For a first characterization of the fiber, we conducted electron microscopic investigations. Figure $2 \mathrm{a}-\mathrm{f}$ depicts different features of the fiber microstructure. A rough, porous structure of the fiber surface and the smooth breaking edge are particularly noticeable. The mean diameter of the fiber thus produced is $56 \mu \mathrm{m}$. Substructures only a few $\mu \mathrm{m}$ in size are visible on the surface and form the basic structure of the fibers. These aggregated structures are in the same size range as the aggregates, which play an important role during the rennetinduced coagulation of CMs [23].

Figure 3a depicts a fluorescence microscopic image taken during a $\mathrm{z}$-scan through a wet fiber $2 \mu \mathrm{m}$ above the fiber surface. Partial labeling of the para-casein micelles in the starting solution allows studying the microstructure of the fibers. Because of homogeneous distribution of the labeled micelles inside the fiber, their whole microstructure can be visualized without having too much fluorescent signal from deeper planes, which would be the case when labeling all micelles. The microstructure is homogeneous over the entire considered area, as shown in Fig. 3a. The porous microstructure consists of a dense gel network, with strand widths in the size range of single micelles. The strands accumulate to granular structures in the size range of a few $\mu \mathrm{m}$. The visualization of the microstructure is important because it affects the mechanical properties of the fibers. The stress-strain curve plotted in Fig. 3 bives information on the mechanical behavior of the fibers. Testing of 4 fibers resulted in a Young's modulus of
Fig. 1 Fabrication of fibers from para-CMs: a casein fiber formed from a cooled para-CM solution after extrusion via a syringe with an attached cannula into a heated, calcium-enriched aqueous solution. b Fiber drawn out of the coagulation bath after $10 \mathrm{~min}$
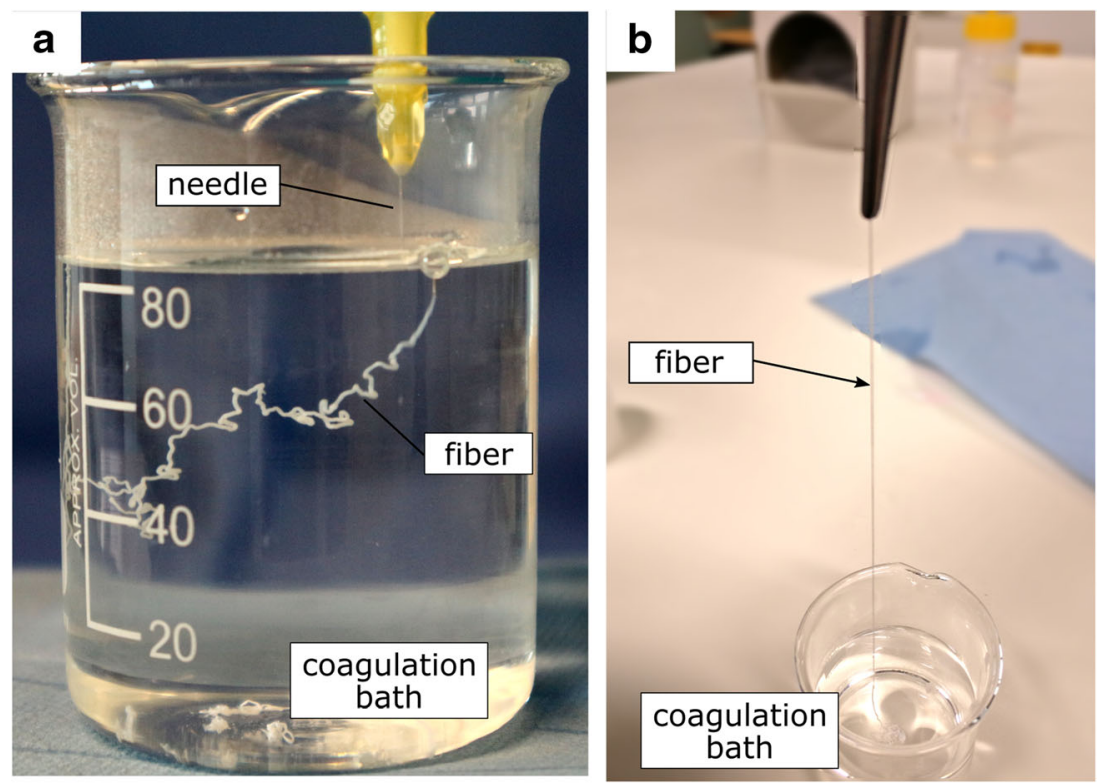

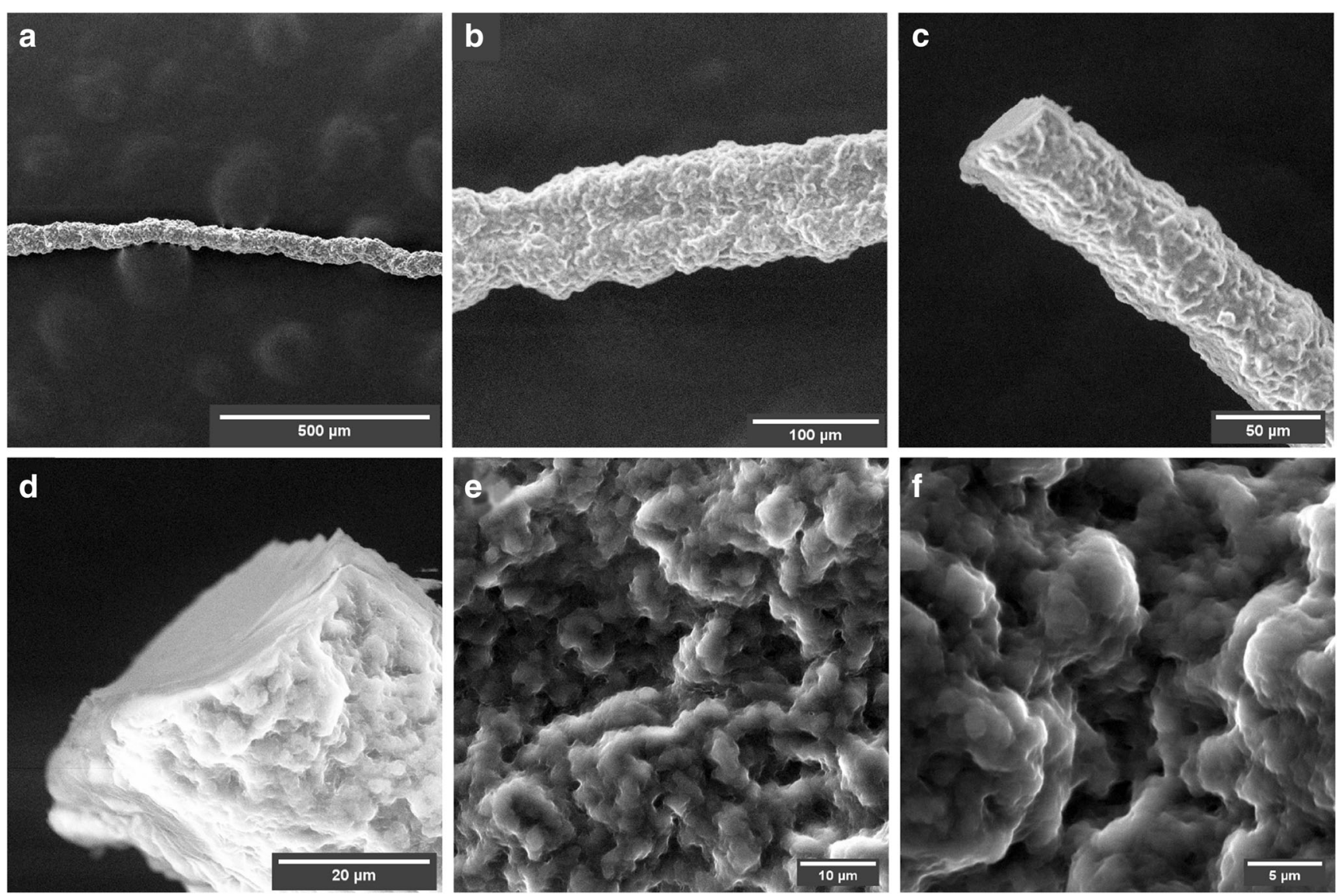

Fig. 2 Electron microscopic images of the dried casein fiber: $\mathbf{a}$ and $\mathbf{b}$ overall structure of the fiber with coarse structuring in the $\mu \mathrm{m}$ range at different magnifications, $\mathbf{c}$ and $\mathbf{d}$ circular cross-section at different

magnifications with smooth surface after fiber breakage, $\mathbf{e}$ and $\mathbf{f}$ microstructure of the fiber surface at higher magnifications

$2.08 \pm 0.26 \mathrm{GPa}$. The linear fit was applied between 0.3 and $1 \%$ stress. Tensile strength is $42.16 \pm 3.17 \mathrm{MPa}$ and breaking elongation is $1.89 \pm 0.61 \%$. With $38 \%$ of tensile strength, $14 \%$ of elongation and 29\% of Young's modulus compared to the casein azlons fabricated by Reddy et al. [6], the micellar fibers show a very brittle behavior. The brittleness results from the low residual water content of the fibers, which dry in air within a few seconds.
To obtain more information about the importance of the aggregates forming the microstructure of the fiber on its overall stability, we investigated the swelling and dissolution behavior in $\mathrm{HCl}$, distilled water, and concentrated $\mathrm{NaOH}$. While the fiber showed no observable changes in $\mathrm{HCl}$ and distilled water, drastic changes in the basic $\mathrm{pH}$ range took place. Figure $4 \mathrm{a}-\mathrm{f}$ shows the swelling behavior of the dried fibers in $1 \mathrm{M} \mathrm{NaOH}$. After only $10 \mathrm{~s}$, a significant increase in fiber
Fig. 3 a Fluoresence microscopic image of the partially labeled fiber. b Exemplary stress-strain curves of the dried fiber and linear fit between 0.3 and $1 \%$ strain
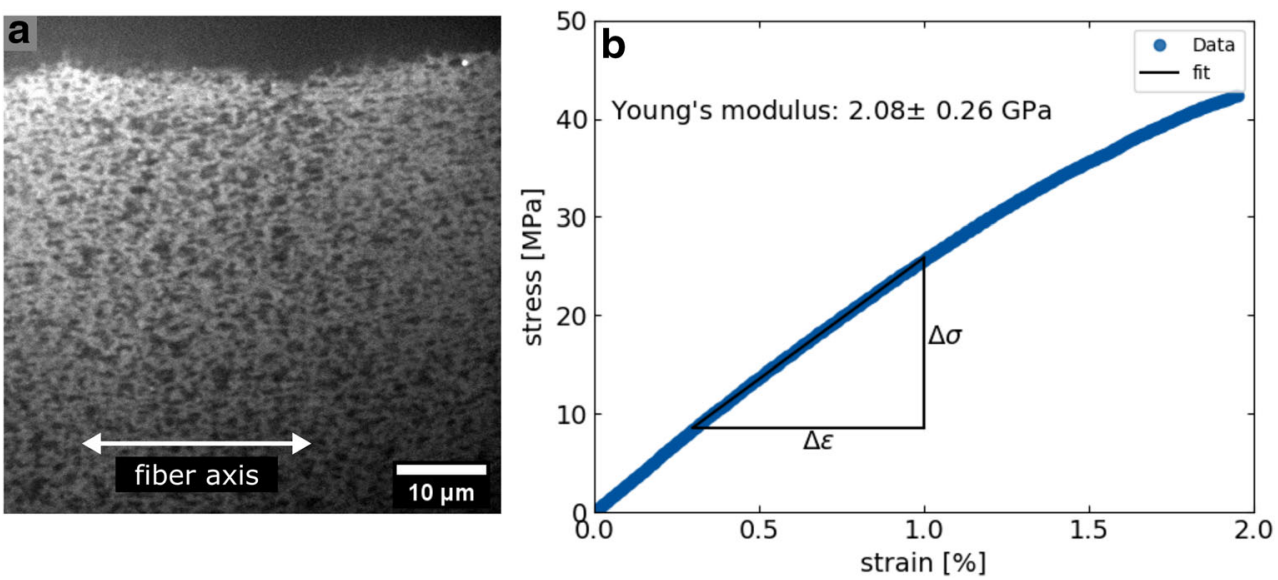
Fig. 4 Time sequence of microscopic images of the swelling (a-e) and decomposition (f) process of the casein fiber after $\mathrm{NaOH}$ posttreatment
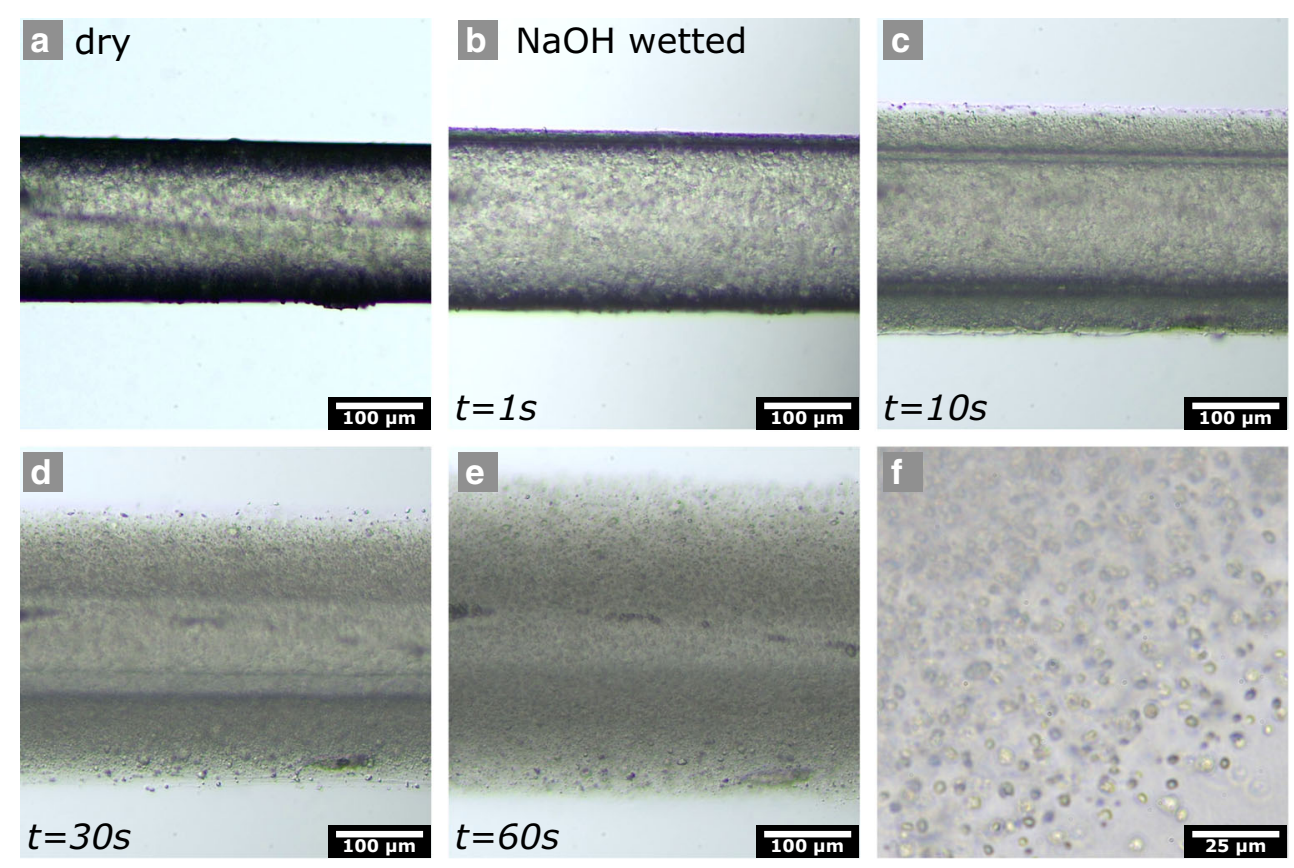

diameter can be observed. In the further course of swelling, the fiber diameter continues to increase, whereby the fiber dissolves more and more, and finally, only spherical objects remain. Due to the similar size, it can be concluded that these objects correspond to the aggregates of the microstructure in Figs. 2 and $3 \mathrm{a}$.

We have recently observed a similar swelling and solubility behavior for casein microparticles [27]. In contrast to the fiber, however, we could not detect aggregates in the $\mu \mathrm{m}$ range after the microparticles had dissolved. The reason for this could be that we had used native CMs instead of para$\mathrm{CMs}$ for the microparticle synthesis and that no strain and shear stress was applied during the manufacturing process.

\section{Conclusion}

In summary, a stable fiber is formed by extruding a cooled para-CM solution into a warm, aqueous calcium chloride solution. Since more stable fibers are formed with increasing temperatures, it can be concluded that the dominant stabilizing interactions within the fiber structure are hydrophobic in nature. The fiber surface possesses a granular microstructure in a size range of a few $\mu \mathrm{m}$. The gel-network structure can be modified in the future with different post-treatment techniques to improve the mechanical properties. In particular, enzymatic crosslinking may enhance water binding capacities and reduce the brittleness. The swelling and dissolution behavior of the fiber and microstructure during post-treatment in $\mathrm{NaOH}$ solution are similar to that recently observed with casein micro particles, whereby, in contrast to the fiber, its $\mu \mathrm{m}$-sized building blocks are made up of native CM. Surprisingly, in the case of the fiber, the aggregates forming the microstructure are extremely $\mathrm{NaOH}$-stable and do not dissolve. This could be due to the fact that the para-CMs, which form loose networks within the aggregates under quiescent conditions [23], assume a more compact structure under the hydrodynamic conditions of the spinning process. However, since the fiber formation took place under slightly different conditions, the influence of particularly the temperature effect will be investigated in more detail. In the future, we want to investigate the fiber formation process in detail by varying the process and environmental conditions and derive structure formation principles to explain and adjust the functional properties of the fibers.

Acknowledgments We thank the Aachener Verfahrenstechnik (AVT) and especially Karin Faensen (AVT.CVT) for her support with the electron microscopy analysis. We also thank Oliver Fiukowsi and Jonas Schneider for their help in the preparation of the samples and the fiber fabrication.

Authors' contributions The manuscript was written through the contributions of all authors. All authors have given approval to the final version of the manuscript.

Funding Open Access funding enabled and organized by Projekt DEAL. This article is funded by the Exploratory Research Space of RWTH Aachen University (project OPSF478). The fluorescence microscopy measurements were supported by the RWTH competence center FLAMENCO (high resolution Fluorescence microscopy Applied in Molecular Science and Engineering COmpetence center) of the profile area MSE.

\section{Compliance with ethical standards}

Conflict of interest The authors declare that they have no conflict of interest. 
Open Access This article is licensed under a Creative Commons Attribution 4.0 International License, which permits use, sharing, adaptation, distribution and reproduction in any medium or format, as long as you give appropriate credit to the original author(s) and the source, provide a link to the Creative Commons licence, and indicate if changes were made. The images or other third party material in this article are included in the article's Creative Commons licence, unless indicated otherwise in a credit line to the material. If material is not included in the article's Creative Commons licence and your intended use is not permitted by statutory regulation or exceeds the permitted use, you will need to obtain permission directly from the copyright holder. To view a copy of this licence, visit http://creativecommons.org/licenses/by/4.0/.

\section{References}

1. Brooks MM (2009) Regenerated protein fibres: a preliminary review. Handbook of Textile Fibre Structure. Elsevier, pp 234-265

2. Muthu SS, Gardetti MA (2016) Sustainable fibres for fashion industry. Springer Singapore, Singapore

3. Southward CR, Walker NJ (1980) the manufacture and industrial use of casein. N Z J Dairy Sci Technol 15:201-217

4. Audic J-L, Chaufer B, Daufin G (2003) Non-food applications of milk components and dairy co-products: a review. Lait 83:417438. https://doi.org/10.1051/lait:2003027

5. Cui L, Reddy N, Xu H, Fan X, Yang Y (2017) Enzyme-modified casein fibers and their potential application in drug delivery. Fibers Polym 18:900-906. https://doi.org/10.1007/s12221-017-1225-3

6. Yang Y, Reddy N (2012) Properties and potential medical applications of regenerated casein fibers crosslinked with citric acid. Int $\mathrm{J}$ Biol Macromol 51:37-44. https://doi.org/10.1016/j.ijbiomac.2012. 04.027

7. Ling S, Qin Z, Li C, Huang W, Kaplan DL, Buehler MJ (2017) Polymorphic regenerated silk fibers assembled through bioinspired spinning. Nat Commun 8:1387. https://doi.org/10.1038/s41467017-00613-5

8. Eisoldt L, Smith A, Scheibel T (2011) Decoding the secrets of spider silk. Mater Today 14:80-86. https://doi.org/10.1016/ S1369-7021(11)70057-8

9. Farrell HM, Qi PX, Uversky VN (2006) New views of protein structure: applications to the caseins: protein structure and functionality. In: Fishman ML, Qi PX, Wicker L (eds) Advances in Biopolymers. American Chemical Society, Washington, DC, pp 52-70

10. Fox PF, Brodkorb A (2008) The casein micelle: historical aspects, current concepts and significance. Int Dairy J 18:677-684. https:// doi.org/10.1016/j.idairyj.2008.03.002

11. Tuinier R, de Kruif CG (2002) Stability of casein micelles in milk. J Chem Phys 117:1290-1295. https://doi.org/10.1063/1.1484379

12. Dalgleish DG, Corredig M (2012) The structure of the casein micelle of milk and its changes during processing. Annu Rev Food Sci Technol 3:449-467. https://doi.org/10.1146/annurev-food-022811101214
13. McMahon DJ, Oommen BS (2008) Supramolecular structure of the casein micelle. J Dairy Sci 91:1709-1721. https://doi.org/10.3168/ jds.2007-0819

14. Horne DS (1998) Casein interactions: casting light on the black boxes, the structure in dairy products. Int Dairy J 8:171-177. https://doi.org/10.1016/S0958-6946(98)00040-5

15. Horne DS (2006) Casein micelle structure: models and muddles. Curr Opin Colloid Interface Sci 11:148-153. https://doi.org/10. 1016/j.cocis.2005.11.004

16. Gebhardt R, Takeda N, Kulozik U, Doster W (2011) Structure and stabilizing interactions of casein micelles probed by high-pressure light scattering and FTIR. J Phys Chem B 115:2349-2359. https:// doi.org/10.1021/jp107622d

17. Horne DS, Lucey JA (2017) Rennet-induced coagulation of milk. Cheese. Elsevier, pp 115-143

18. Mezzenga R, Schurtenberger P, Burbidge A, Michel M (2005) Understanding foods as soft materials. Nat Mater 4:729-740. https://doi.org/10.1038/nmat1496

19. Sandra S, Ho M, Alexander M, Corredig M (2012) Effect of soluble calcium on the renneting properties of casein micelles as measured by rheology and diffusing wave spectroscopy. J Dairy Sci 95:7582. https://doi.org/10.3168/jds.2011-4713

20. Bansal N, Fox PF, McSweeney PLH (2007) Aggregation of rennetaltered casein micelles at low temperatures. J Agric Food Chem 55: 3120-3126. https://doi.org/10.1021/jf0631427

21. Horne DS, Lucey JA (2014) Revisiting the temperature dependence of the coagulation of renneted bovine casein micelles. Food Hydrocoll 42:75-80. https://doi.org/10.1016/j.foodhyd.2013.12. 021

22. Heidebach T, Först P, Kulozik U (2009) Microencapsulation of probiotic cells by means of rennet-gelation of milk proteins. Food Hydrocoll 23:1670-1677. https://doi.org/10.1016/j.foodhyd.2009. 01.006

23. Thill S, Schmidt T, Wöll D, Gebhardt R (2020) Single particle tracking as a new tool to characterise the rennet coagulation process. Int Dairy J:104659. https://doi.org/10.1016/j.idairyj.2020. 104659

24. Sudha TB, Thanikaivelan P, Ashokkumar M, Chandrasekaran B (2011) Structural and thermal investigations of biomimetically grown casein-soy hybrid protein fibers. Appl Biochem Biotechnol 163:247-257. https://doi.org/10.1007/s12010-010-9034-9

25. Tomasula PM, Sousa AMM, Liou S-C, Li R, Bonnaillie LM, Liu LS (2016) Short communication: electrospinning of casein/pullulan blends for food-grade applications. J Dairy Sci 99:1837-1845. https://doi.org/10.3168/jds.2015-10374

26. Dumpler, J. (2018) Heat Stability of Concentrated Milk Systems. Springer Fachmedien Wiesbaden. https://doi.org/10.1007/978-3658-19696-7

27. Schulte J, Stöckermann M, Gebhardt R (2020) Influence of pH on the stability and structure of single casein microparticles. Food Hydrocoll 105:105741. https://doi.org/10.1016/j.foodhyd.2020. 105741

Publisher's note Springer Nature remains neutral with regard to jurisdictional claims in published maps and institutional affiliations. 